\title{
Belgeo
}

Revue belge de géographie

\section{Art et culture à Ramallah dans les Territoires palestiniens occupés (TPO): Entre patrimoine, revendications politiques et développement territorial}

Art and culture in Ramallah and the occupied Palestinian territories (OPT):

between heritage, political claims, and territorial development

Pauline Bosredon, Sophie Gravereau, Marie-Thérèse Grégoris et Anissa Habane

\section{(2) OpenEdition \\ Journals}

\section{Édition électronique}

URL : http://journals.openedition.org/belgeo/13392

DOI : 10.4000/belgeo.13392

ISSN : 2294-9135

\section{Éditeur :}

National Committee of Geography of Belgium, Société Royale Belge de Géographie

\section{Référence électronique}

Pauline Bosredon, Sophie Gravereau, Marie-Thérèse Grégoris et Anissa Habane, « Art et culture à Ramallah dans les Territoires palestiniens occupés (TPO): Entre patrimoine, revendications politiques et développement territorial », Belgeo [En ligne], 3 | 2014, mis en ligne le 19 décembre 2014, consulté le 19 avril 2019. URL : http://journals.openedition.org/belgeo/13392 ; DOI : 10.4000/belgeo.13392

Ce document a été généré automatiquement le 19 avril 2019.

Belgeo est mis à disposition selon les termes de la licence Creative Commons Attribution 4.0 International. 


\section{Art et culture à Ramallah dans les Territoires palestiniens occupés (TPO): Entre patrimoine, revendications politiques et développement territorial}

Art and culture in Ramallah and the occupied Palestinian territories (OPT):

between heritage, political claims, and territorial development

Pauline Bosredon, Sophie Gravereau, Marie-Thérèse Grégoris et Anissa Habane

\section{Introduction}

1 Dans le contexte de grande instabilité politique et d'occupation qui caractérise les Territoires Palestiniens Occupés (TPO), les villes apparaissent aujourd'hui comme des espaces cruciaux où se jouent l'affirmation politique et le développement culturel et social d'une nation en devenir. Depuis les accords d'Oslo en 1993, les politiques en matière d'art et de culture menées à Ramallah, capitale refuge de l'Autorité palestinienne, à défaut de Jérusalem-Est, témoignent de cette volonté de réinvestir les centres-villes et de construire une dynamique culturelle et urbaine. L'école de musique Al-Kamandjâti, le centre d'arts visuels Hosh Qandah, l'Ottoman Court, à la fois bibliothèque et lieu d'exposition, la maison culturelle Dar Zahran, etc. sont autant d'espaces consacrés à l'art et à la culture, localisés dans le centre ancien de Ramallah, en Cisjordanie, qui évoquent l'histoire politique de la ville, son patrimoine, ainsi que son statut récent de centre politique et décisionnel. Produire de nouveaux lieux permet de mettre en avant l'existence d'un nouveau territoire. Ces lieux sont à la fois les témoins d'un passé révolu et des lieux produits et construits, à travers les différents événements qu'ils proposent, pour signifier la possibilité d'un avenir différent. Quels enjeux culturels, économiques, patrimoniaux, politiques et sociaux sous-tendent de telles opérations ? Dans quelle 
mesure la création de nouveaux espaces artistiques participe-t-elle à la construction de l'image d'une ville ou d'un territoire ? Comment expliquer les récentes transformations de la vieille ville de Ramallah en lieu d'accueil d'associations culturelles palestiniennes et internationales, représentatives d'une identité territoriale et nationale attractive?

2 La vieille ville n'est évidemment pas le seul espace culturel de la ville, mais compte tenu de l'attention particulière que lui portent les acteurs publics et privés pour son patrimoine architectural et en raison de sa forte valeur culturelle et symbolique, nous choisissons délibérément dans cet article de nous focaliser sur cet espace où convergent les politiques municipales en faveur de la culture, du développement social et de la mise en valeur patrimoniale. La Municipalité de Ramallah a en effet profité d'opportunités foncières et immobilières dans la vieille ville pour appuyer sa politique culturelle sur la réhabilitation d'un certain nombre d'édifices remarquables. Ce qui nous intéresse ici c'est de comprendre les mécanismes à travers lesquels les acteurs associatifs, individuels et politiques locaux, nationaux, voire internationaux, cherchent à créer une nouvelle centralité culturelle au cœur des TPO. Notre propos se base sur une analyse bibliographique, des observations sur le terrain ${ }^{1}$ ainsi que des entretiens avec des acteurs locaux et internationaux (institutionnels et non institutionnels) impliqués dans le champ de la culture.

\section{Culture et territoires en Palestine : résistance et revendications politiques}

\section{Un contexte urbain singulier}

3 Avec 65000 habitants en $2007^{2}$, l'agglomération Ramallah-Al Bireh n'est que la troisième de Cisjordanie, après les villes d'Hébron (166 063) et Naplouse (134 116). En 1995, elle devient la « capitale malgré elle » des territoires sans Etat de la Palestine (Heackock R., 2013 ; Barthe B., 2011). La présence d'un des deux QG de Yasser Arafat (le second étant à Gaza) et sa proximité avec Jérusalem-Est, la capitale revendiquée, justifient l'implantation $\mathrm{du}$ nouveau parlement, du siège présidentiel et des administrations de la nouvelle Autorité palestinienne. Dès lors, les représentations (ONG, consulats) des nombreux organismes internationaux viennent compléter ces fonctions administratives et politiques.

En dépit de cette centralité, la ville de Ramallah demeure un territoire enclavé, cerné par des limites établies par les accords d'Oslo en 1993 et par les occupations spatiales israéliennes. Les accords d'Oslo puis les accords de Taba (1995) entérinent la création d'une autorité palestinienne dotée de structures politiques et administratives (Porteilla, Fontaine, Icard, Larceneux, 2011). Depuis, ce qui devait être temporaire s'est mué en statut de longue durée, transformant la Palestine en «territoire en archipels ». Trois zones sont ainsi déterminées : la zone $\mathrm{A}$ est celle où l'Autorité palestinienne a la totalité des responsabilités liées à la ville et au maintien de l'ordre; la zone B est sous contrôle palestinien sauf pour la sécurité qui relève des autorités israéliennes; la zone $C$ est exclusivement sous contrôle israélien. Cette dernière comprend Jérusalem-Est qui est isolée du reste de la Cisjordanie. Ramallah - comme les villes de Bethléem, Jénine, Qalqilya, Naplouse, Tulkarem, Jéricho et une partie de la bande de Gaza - est située en zone A, ce qui lui confère une certaine autonomie. Elle ne dispose pourtant pas de toutes les libertés pour se développer, le processus de création d'un Etat palestinien étant bloqué 
depuis 2000. Les possibilités de croissance de Ramallah sont également freinées par la présence des colonies, toujours plus nombreuses et imposantes aux limites de la zone A, et de la proximité de Jérusalem-Est, capitale revendiquée de l'Autorité palestinienne, mais inaccessible - sauf exception - aux Palestiniens venant de Cisjordanie et de la Bande de Gaza. En dépit de cette situation d'enfermement politique et spatial, la ville de Ramallah se développe et demeure un espace de résistance au cœur des TPO.

\section{La culture comme outil de résistance politique et territorial}

5 Les acteurs palestiniens que nous avons rencontrés au cours de notre enquête revendiquent à l'unisson la culture comme outil de résistance et d'affirmation identitaire face à l'occupation israélienne. Pour les responsables de l'ONG Al-Kamandjâti, dont l'objectif est d'enseigner et de transmettre la musique classique aux Palestiniens, l'art et la culture sont incontestablement des outils politiques: "La musique est un langage universel. Avec cet outil artistique, le peuple palestinien peut transmettre sa culture, promouvoir son identité et faire en sorte que les autres peuples du monde le reconnaissent en tant que nation ${ }^{3}$ ». L'association débute ses activités en 2002, dans des lieux sensibles, aux conditions difficiles, comme Hébron et Gaza, le check-point de Qalandia et les camps de réfugiés. Pour Nabil El-Haggar, réfugié palestinien et acteur culturel en France, « Aux Palestiniens, il ne reste que la culture et l'éducation pour rester debout, se sentir individuellement responsable et penser leur humanité afin de pouvoir la préserver » (El-Haggar, 2004, p. 53). La culture, mais également l'art, sont utilisés par les Palestiniens comme une " $\mathrm{arme}^{4}$ » au service de la résistance à l'occupation israélienne.

Les acteurs des mondes de l'art et les responsables des institutions culturelles multiplient les actions porteuses d'un message politique fort, l'objectif étant de dénoncer les effets de l'occupation et de donner une résonnance à leur situation dans les TPO. Installé à Ramallah, Khaled Jarrar, 35 ans, réalise des performances vidéos témoignant de la situation politique palestinienne: Journeys 110 montre un passage d'égouts entre la Cisjordanie et Jérusalem, où des hommes, chaussés de sacs en plastique, descendent dans les entrailles de la ville jusqu'à ce qu'une voix leur dise que «le tunnel est fermé ». Pour l'artiste, « l'art est plus fort que le pouvoir et l'armée. Il permet de montrer une réalité sociale» (cité dans Debras, 2011). La création artistique contemporaine vient ainsi renforcer le message politique en donnant un sens nouveau à la résistance : pour Nabil ElHaggar, cette résistance artistique et culturelle devient le «socle sur lequel la société palestinienne devrait poser son projet pour lutter contre l'occupation et construire son avenir » (El-Haggar, 2004, p. 47).

\section{La vieille ville de Ramallah : un territoire émergeant d'une politique culturelle et patrimoniale}

\section{Un projet municipal visant à faire renaître la vieille ville}

7 Située sur une colline, à l'est de l'hypercentre, la vieille ville de Ramallah s'inscrit dans les limites du village originel. A la différence des autres villes palestiniennes, la ville de Ramallah n'existait pas sous l'Antiquité. Son histoire, qui ne se dessine qu'à partir du XVI ème siècle, est celle d'un village devenu bourgade commerçante. Aussi le patrimoine bâti de la vieille ville est-il composé essentiellement de maisons, soit des hosh ${ }^{5}$ de la période 
ottomane, soit des maisons bourgeoises construites à partir de la fin du XIX ème siècle. Ce patrimoine n'est pas protégé car la législation actuelle ne le permet pas, il est cependant en cours de réhabilitation sous l'impulsion de Riwaq, une association palestinienne fondée en 1991 pour la sauvegarde du patrimoine bâti (Habane et al., 2012), et de revitalisation grâce aux efforts déployés par la Municipalité de Ramallah pour y installer des activités culturelles. Le département d'urbanisme a décidé au début des années 2000 d'impulser la mise en valeur du tissu ancien par la réhabilitation complète de quatre édifices jusqu'alors laissés à l'abandon, parmi lesquels deux sont placés sous régie directe du Département municipal des affaires sociales et culturelles et deux sont occupés par des associations (Al-Kamandjâti, figure 3, et le Tamer Institute). Les travaux furent confiés à la Riwaq, qui opéra grâce au soutien financier de l'Agence internationale suédoise de coopération et de développement (SIDA). Dans l'objectif de redonner vie et usage à ces bâtiments, la Municipalité joua un rôle de facilitateur en mettant en lien les propriétaires respectifs des édifices avec les deux associations qui obtinrent des baux de location de longue durée. L'espoir de la Municipalité était alors que l'installation de ces deux premiers équipements, une école de musique et un centre culturel pour les enfants de la vieille ville et plus largement de tout Ramallah, provoquerait un certain effet boule de neige ${ }^{6}$ et inciterait d'autres propriétaires à entreprendre la réhabilitation de leur bien et d'autres associations à s'installer dans le quartier (figure 2).

Figure 1. Les structures et les équipements culturels de l'agglomération de Ramallah.

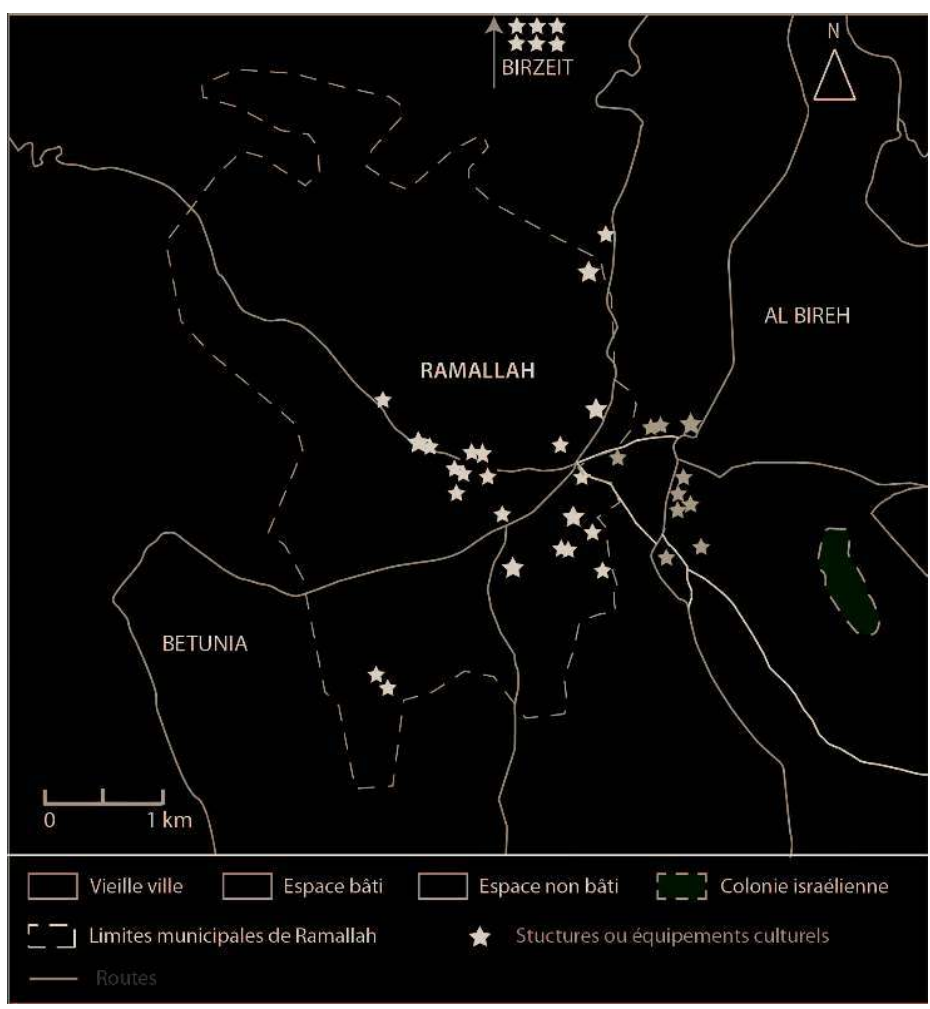

LA CARTE CI-DESSUS MONTRE UNE ASSEZ gRANDE DISPERSION DES ÉQUIPEMENTS DANS TOUTE LA VILLE DE RAMALLAH, ET PAS DE SPÉCIALISATION NETTE D'UN QUARTIER EN PARTICULIER.

RÉALISATION : P. BOSREDON ET A. HABANE, 2014. SOURCE : THIS WEEK IN PALESTINE, MARS 2014. 
Figure 2. Les structures et les équipements culturels de la vieille ville de Ramallah.

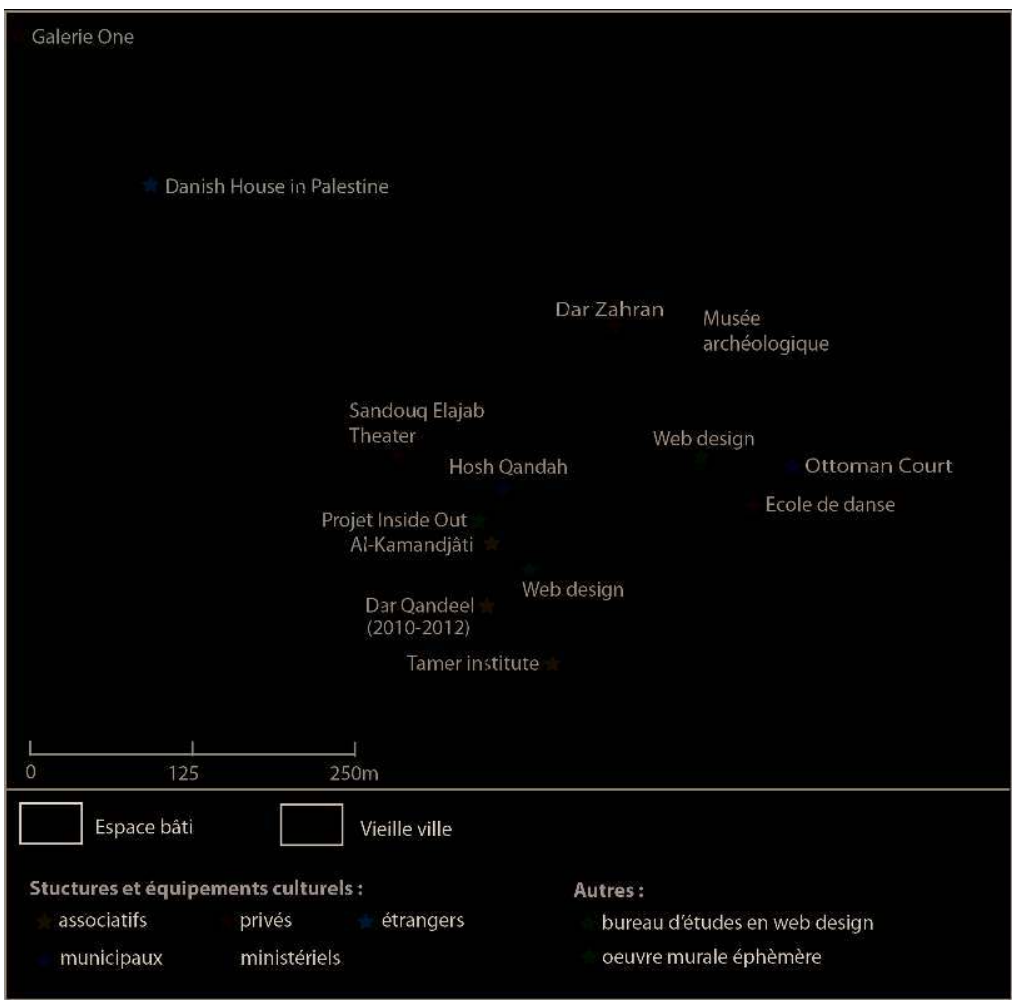

RÉALISATION : A. HABANE, 2014. SOURCE : RELEVÉs PERSONNELS, 2014. 
Figure 3. Photographie de la façade extérieure du bâtiment accueillant l'association Al-Kamandjâti.

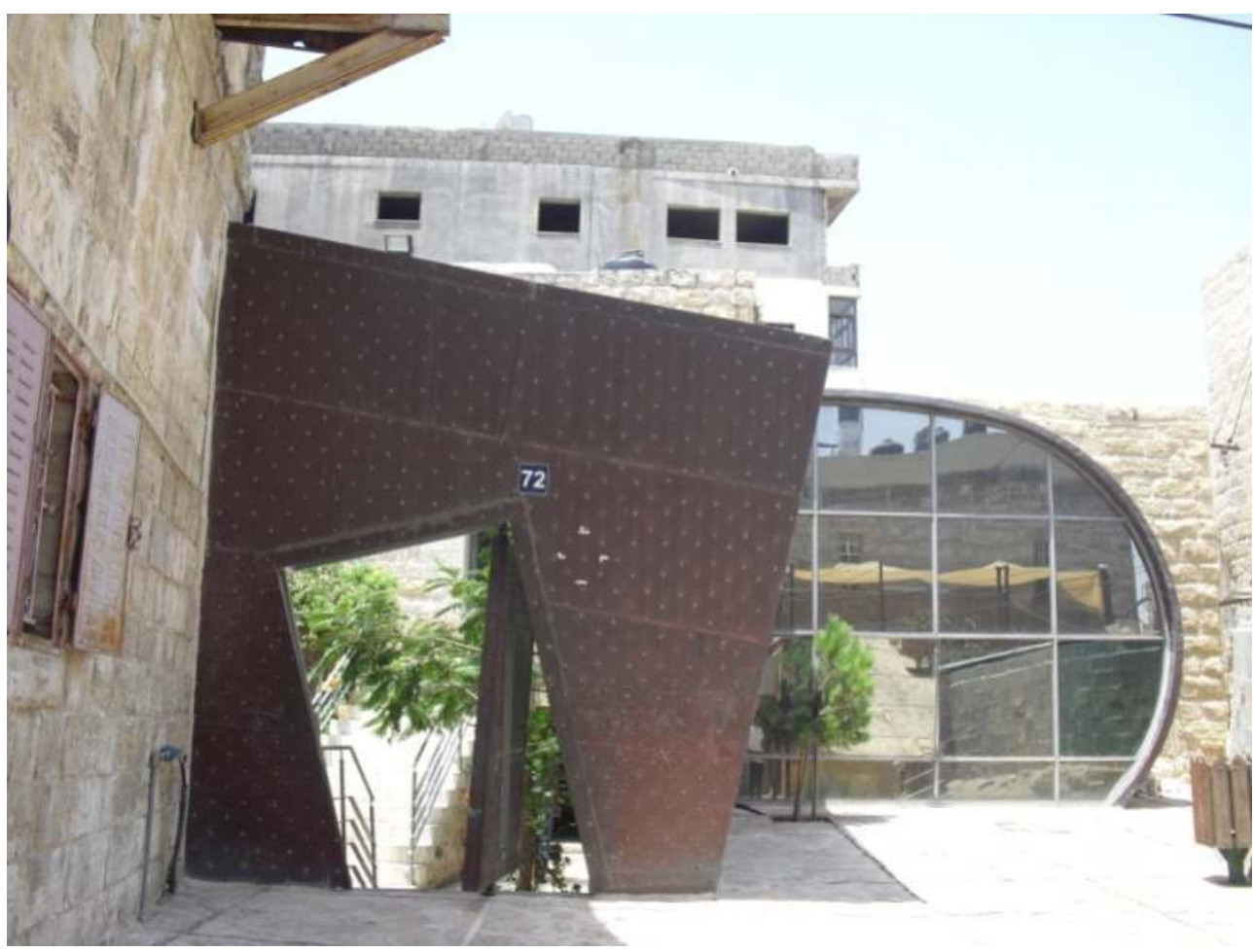

Réalisation Anissa Habane, 2011

Avant sa réhabilitation, le bâtiment historique de l'époque ottomane qui abrite désormais Al-

Kamandjâti était utilisé comme une décharge par les habitants de la vieille ville depuis plus de dix ans. Il fallut dix camions pour évacuer les déchets qui tapissaient le bâtiment et son patio (Bshara, 2005). Le bâtiment historique a fait l'objet d'une restauration en 2005 (première phase), d'une extension en 2007 (seconde phase), et d'une modernisation de son architecture avec des ajouts très contemporains (verre, métal) au niveau de la porte d'entrée, de la façade et du toit.

La mairie est aussi un acteur direct de la programmation et de l'animation culturelle comme le prouve son installation dans les deux autres édifices: l'Ottoman Court et le Hosh Qandah. L'Ottoman Court, restauré en 2002, héberge aujourd'hui une bibliothèque pour enfants et un " dialogue café », et dispose d'un petit amphithéâtre extérieur qui sert à des projections ou à des spectacles en plein air. Quant au Hosh Qandah, il va devenir prochainement le premier studio en arts visuels de Ramallah. Le projet a dû faire face à l'hostilité première des riverains. Il était en effet question au départ pour la Municipalité de mettre en place une résidence d'artistes mais l'idée n'a pas été bien accueillie par les habitants de la vieille ville qui ne souhaitaient pas que les artistes dorment sur place. Des membres de l'association Dar Qandeel for Arts and Culture nous ont raconté avoir eu des conflits avec les habitants de la vieille ville de Ramallah après que des bénévoles étrangers soient restés dormir dans la maison historique qui accueillait l'antenne de leur association en fonctionnement entre 2010 et 2012. ${ }^{7}$ A travers cet exemple, on relève la tension entre la fonction résidentielle de la vieille ville et le développement des activités culturelles ouvrant sur des modes de vie différents. La Municipalité a de ce fait renoncé à faire du Hosh Qandah une véritable résidence d'artistes. Ces derniers, sélectionnés par la Municipalité tous les deux ans parmi les artistes de Ramallah (ce qui rend caduque le problème de leur hébergement), s'engageront à organiser un certain nombre d'ateliers artistiques et techniques avec les habitants (notamment ceux de la vieille ville) à côté de leur projet personnel. La mairie organisera parallèlement un programme mensuel 
d'activités artistiques (musique, théâtre, poésie...) : selon les dires de Sally Abubakar ${ }^{8}$, il s'agira véritablement d'un "centre social et artistique». Son principal défi reste cependant la participation des habitants au projet, seule garantie de leur pleine acceptation du nouvel équipement et de la présence des artistes dans leur voisinage. La Municipalité a en effet décidé d'utiliser les unités d'habitation qui se trouvent autour de la cour centrale qui forme le Hosh Qandah. Elle a pour cela racheté les bâtiments à leurs propriétaires et a dû négocier" avec les locataires des lieux l'utilisation du niveau inférieur, leur proposant de fait une cohabitation qui fut longue à accepter.

9 Les différents acteurs de la culture dans la vieille ville, qu'ils soient municipaux, privés ou associatifs, travaillent étroitement ensemble, et les observations sur le terrain ont permis de constater que de fréquentes réunions les réunissaient dans les locaux municipaux de l'Ottoman Court. Dans ce cadre, l'association Al-Kamadjâti, qui jouit d'une renommée internationale, est le partenaire stratégique de la Municipalité ${ }^{10}$. Cette dernière affirme essayer aujourd'hui d'associer d'autres structures culturelles et encourager les synergies. Une attention particulière est enfin accordée à l'appropriation de l'espace public où la mairie essaie de développer des activités. L'espace public, les places, les rues, étaient très peu investis par les activités sociales et culturelles auparavant, en tout cas depuis 1967 et depuis l'occupation israélienne. Selon Sally Abubakar, l'occupation de l'espace public ne concerne pas que l'installation d'œuvres d'art ou l'organisation d'événements culturels : cela revient à aider les habitants à affirmer qu'ils sont citoyens de cette ville et qu'ils ont le droit d'utiliser cet espace. Les fresques qui ornent de nombreuses façades ont par exemple été réalisées par les enfants du Tamer Institute. Autre exemple : en 2012, pour le festival Wein a Ramallah (figure 4), l'ONG Riwaq a installé dans la rue un poster représentant le plan de la vieille ville et a invité les enfants à redessiner la vieille ville comme ils la rêvent (avec des espaces verts, de hauts buildings). 
Figure 4. Festival Wein a Ramallah.

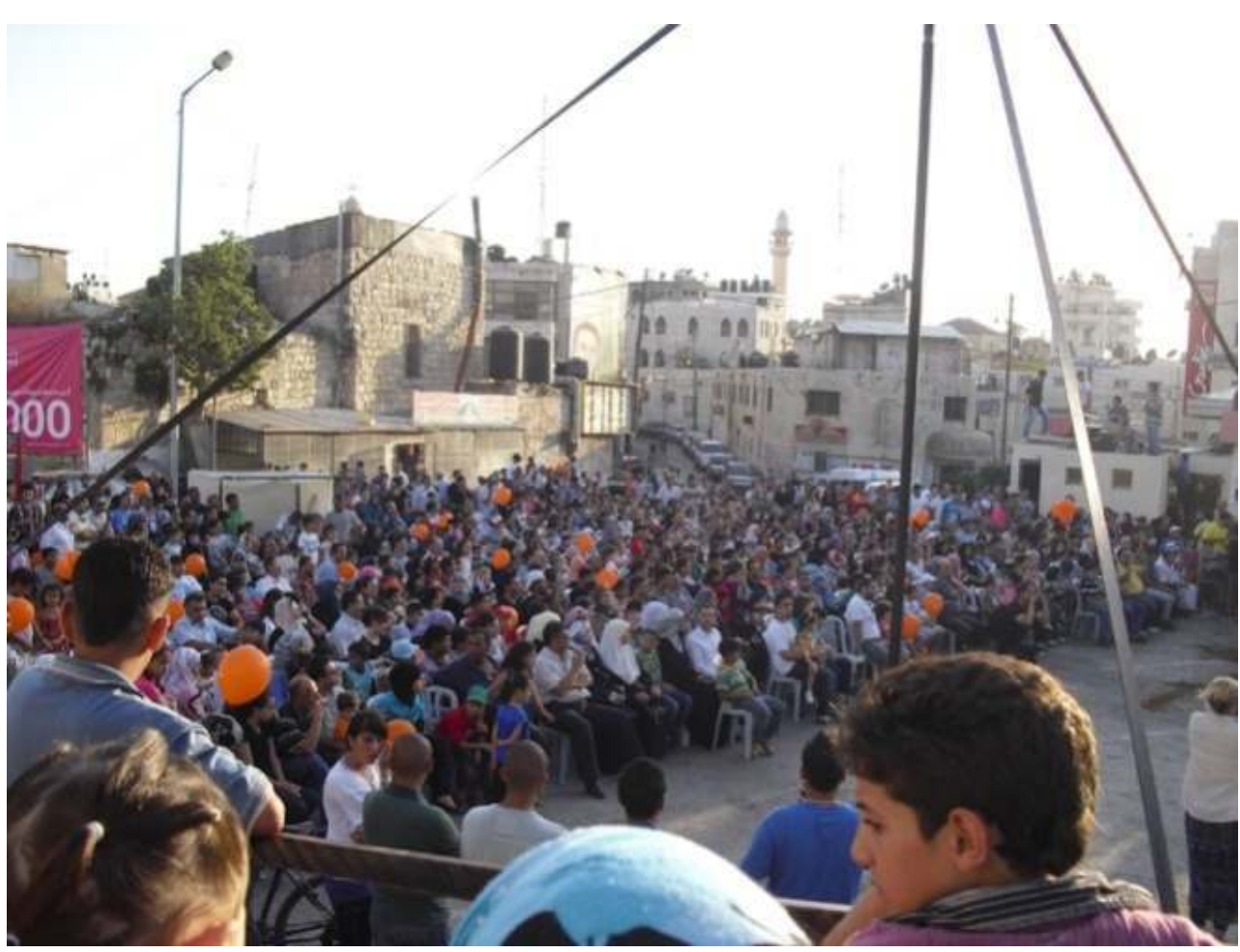

Réalisation Anissa Habane, 2011

10 A terme, Sally Abubakar explique que la vieille ville a pour vocation de devenir un véritable quartier culturel de Ramallah. Beaucoup reste encore à faire cependant, et avant de pouvoir parler de la vieille ville comme du cœur culturel de Ramallah, il est nécessaire de redonner du sens et une image positive à ce quartier qui fut pendant longtemps laissé en marge du développement économique et urbain. «Dans l'avenir, je suis sûre que la vieille ville deviendra le quartier culturel central de Ramallah, mais ce n'est pas encore le cas aujourd'hui. Nous devons encore travailler avec les habitants, ces derniers doivent accepter nos projets et il faut qu'ils y participent. Nous ne pouvons pas nous contenter d'arriver comme ça et de faire les choses. Nous devons travailler avec eux. C'est la raison pour laquelle beaucoup d'institutions travaillent avec les enfants : ça commence par là ! Mais notre plan, c'est vraiment de faire de la vieille ville une centralité culturelle ${ }^{11}$ ». L'expérience de la vieille ville de Ramallah se distingue des autres villes palestiniennes par la volonté de la Municipalité, des artistes, des mécènes, des investisseurs et des bénévoles de déployer l'art et la culture au sein de la vieille ville. Cette démarche participe au développement d'une nouvelle image de la vieille ville et contribue à son rayonnement et à son attractivité.

\section{Développement de lieux culturels individuels et périphériques}

11 L'enquête que nous avons réalisée à Ramallah a révélé l'existence, dans la vieille ville et son étroite périphérie, de lieux culturels portés par des initiatives individuelles en dehors de tout soutien institutionnel. Dar Zahran Heritage Building est un espace artistique, situé dans l'ancienne demeure familiale Dar Zahran Jaghab, réhabilitée et transformée par un des descendants, propriétaire des lieux. Il s'agit d'une maison de style ottoman 
transformée en 2012 en espaces dédiés à l'art et la culture : une galerie permanente où sont présentées d'anciennes photos de Ramallah entre 1850 et 1979; une salle d'exposition temporaire présentant des productions d'artistes palestiniens ou arabes israéliens; une boutique de souvenirs mettant en vente des produits artisanaux palestiniens (broderies, produits alimentaires, bijoux, céramique) et un sous-sol dédié à une série de manifestations culturelles et artistiques. Pour le propriétaire des lieux, graphiste, soucieux de conserver une indépendance vis-à-vis des institutions ${ }^{12}$, la ville de Ramallah offre les opportunités pour développer ce type d'initiative dans le champ de la culture. La ville bénéficie d'un milieu culturel local, en demande de manifestations dans le domaine de l'art.

Une galeriste, travaillant à Londres et récemment installée en périphérie de la vieille ville, dans un immeuble où se situe en rez-de-chaussée un café réputé chez les Ramallawis les plus aisés, confirme l'existence d'un public local pour la culture et plus encore d'une clientèle pour un marché de l'art en devenir. Le premier vernissage, marquant l'ouverture de sa galerie, a permis la vente de plusieurs toiles d'artistes palestiniens reconnus ${ }^{13}$. Le travail de recherche effectué par Marion Slitine sur «Les "mondes de l'art" contemporain palestinien au prisme du politique: anthropologie des artistes plasticiens en Territoires palestiniens » démontre également le dynamisme de Ramallah en matière de réseaux artistiques et culturels (Slitine, 2013) : à l'échelle locale, celle des lieux d'art de la ville, et à l'échelle internationale, celle des galeries promouvant des créateurs palestiniens. La ville de Ramallah est devenue un lieu de ressource et de transmission culturelle où le développement de la culture permet un dynamisme social et économique.

\section{Développement culturel de Ramallah : s'affirmer face à Jérusalem}

\section{Ramallah au cœur d'une nouvelle cartographie culturelle?}

Une analyse du périodique mensuel This week in Palestine nous offre la possibilité de cartographier (ci-dessous figure 5), la répartition des structures et des équipements culturels à l'échelle des villes palestiniennes. Nous avons recouru à cette source d'informations car il n'existe pas de données complètes sur les structures et les équipements culturels présents en Cisjordanie. Le Palestinian Central Bureau of Statistics ${ }^{14}$ (PCBS) avance un nombre de centres culturels passé de 83 en 1998, à 227 en 2007 et à 597 en 2011. Ces statistiques sont intéressantes car elles révèlent la progression rapide du nombre de centres culturels en une décennie. Cependant, nous ne savons pas à quoi renvoie la typologie "centres culturels", il nous a donc été impossible d'exploiter ces statistiques pour la cartographie. De plus, les données du PCBS sont avancées à l'échelle régionale de la Cisjordanie et de la Bande de Gaza. This week in Palestine a l'avantage de dénombrer et nommer les structures et équipements culturels existants à l'échelle de l'agglomération ou de la commune en Cisjordanie et dans la Bande de Gaza, même si ces données présentent des lacunes: celles de Jérusalem-Est, Ramallah et Bethléem sont détaillées d'une manière exhaustive alors que celles des autres villes de Cisjordanie sont incomplètes ou inexistantes. L'atout principal de cette publication est qu'elle est mise en ligne depuis sa date de création en $1998^{15}$ et complétée par un livret papier (distribué dans les hôtels, dans les centres culturels etc.). L'ensemble est rédigé en anglais dans un 
souci de diffusion aux Palestiniens eux-mêmes mais aussi aux visiteurs (returnees et internationaux), ce qui montre bien l'ambition d'ouverture et d'attractivité des acteurs palestiniens de la culture aujourd'hui. La lecture de This week in Palestine nous a permis de saisir les grandes disparités en matière de culture à l'échelle de la Cisjordanie: les structures culturelles sont en effet très inégalement réparties et principalement concentrées dans les villes de Ramallah, Jérusalem et Bethléem. Outre le développement des équipements consacrés à l'art et à la culture, Ramallah, Jérusalem et Bethléem ont multiplié les festivals - fête de l'olive, Wein a Ramallah ou Nouware Nissane pour la ville de Ramallah - dynamisant ainsi le paysage culturel palestinien.

Figure 5. Les structures et les équipements culturels dans les villes palestiniennes.

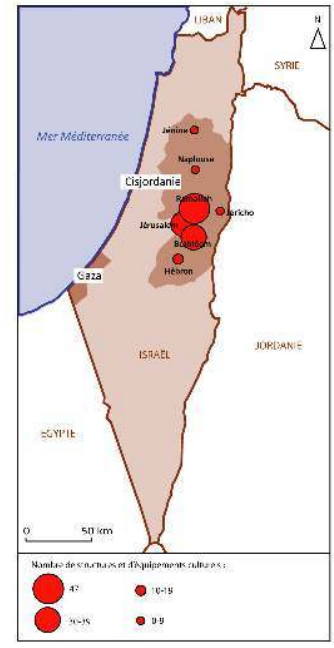

Réalisation : P. Bosredon, 2014. Sources : This week in Palestine, mars 2014 et Philippe Rekacewicz, Le Monde diplomatique, 1998.

14 Il semble que la ville de Ramallah, dans le jeu de la concurrence interurbaine (triangle Bethléem - Jérusalem - Ramallah), occupe la place principale. En témoignent les propos d'un habitant de Naplouse travaillant à Ramallah : "Les habitants de Ramallah et Jérusalem sont plus riches qu'à Naplouse. Ramallah est considérée comme le Paris de la Palestine. Il y a l'idée de véhiculer et de préserver un prestige entre les familles de Ramallah. Les businessmen investissent beaucoup dans Ramallah car c'est là qu'il y a leurs réunions, il y a aussi les ministères, etc. On encourage les étrangers à visiter d'abord Ramallah et ensuite les autres villes ${ }^{16} »$. Le dernier This week in Palestine, ${ }^{\circ} 202$ de février 2015, consulté en ligne, nous permet également de saisir l'effervescence culturelle dont jouit la ville : la récurrence, la diversité et la fréquence des événements sont supérieures à celles observées dans les autres villes de Cisjordanie.

L'événementiel en matière d'art et de culture est en effet au cœur de la politique municipale, fruit de la volonté palestinienne (ONG, fondations, municipalités, artistes), 
d'initiatives étrangères (individus, artistes, associations, fondations, collectivités publiques, régions, pays, représentations étrangères) ou de partenariats privés locaux et internationaux. Le festival annuel Wein a Ramallah, crée dans les années 2010 par la Municipalité de Ramallah, mène, via la réalisation de workshops, une réflexion sur la culture dans les Territoires palestiniens occupés. En juillet 2010, le thème du workshop, réunissant des représentants des municipalités de Cisjordanie, du Ministère de la Culture et du Ministère du Gouvernement local, portait sur les gouvernements locaux et le développement culturel. En 2011, les deux journées de conférences étaient consacrées à Ramallah et son développement culturel: "Ramallah, capitale culturelle de la Palestine? », pouvait-on lire dans le programme.

Le rayonnement de Ramallah se voit également à travers une concentration de musées régionaux et nationaux. L'étude du journal This Week in Palestine complétée par un inventaire que nous avons réalisé, révèle une trentaine de musées répartis dans l'ensemble de la Cisjordanie, dont une majorité se trouve dans l'agglomération de Ramallah. Les lieux et les missions alloués aux musées nous permettent de saisir comment le rayonnement prend appui dans la ville, quelles valeurs et quels symboles ces musées diffusent, à destination de quels publics et de quels territoires. Plus que les collectivités territoriales, ce sont l'Autorité palestinienne, des fondations privées ou des Universités qui sont à l'origine de ces musées archéologiques, ethnographiques ou commémoratifs. Le Ministère du Tourisme et des Antiquités établit le Ramallah Museum en 1998. Les fondations gestionnaires du musée Mahmoud Darwich et du musée Yasser Arafat sont créées toutes les deux par décret présidentiel en 2008. Le futur Palestinan Museum, en cours de construction à Birzeit, est porté par la Welfare Association. Toujours à Birzeit, l'Université accueille dans ses murs un musée conçu à partir d'un legs de robes et d'amulettes de l'anthropologue Taoufik Kanaan. Les lieux réservés à ces équipements sont précieux et hautement symboliques: une maison bourgeoise dans la vieille ville témoignant de la première expansion de Ramallah à la fin du XIXème siècle ; l'emplacement de l'ancienne Mouqataa (le quartier général gouvernemental) où Yasser Arafat a été assiégé en 2002 ; un bâtiment contemporain sur un site de 3 ha au sommet d'une colline pour le musée Darwich; $40000 \mathrm{~m}^{2}$ d'anciennes terrasses cultivées dans la banlieue, à Birzeit ; $400 \mathrm{~m}^{2}$ de surfaces d'exposition dans l'Université de Birzeit. Les discours de présentation de ces musées révèlent une mission qui leur est commune : préserver et promouvoir un patrimoine et une identité palestinienne, et diffuser des valeurs de résistance, d'amour de la patrie et de dignité humaine, plus précisément pour les deux musées commémoratifs. De cette manière ils ont une vocation éducative et s'adressent à des publics scolaires cisjordaniens. Mais le public globalement visé, lorsque les supports électroniques le permettent, est géographiquement plus dispersé : c'est le peuple palestinien, qui vit en Cisjordanie, à Gaza, en Israël, et ailleurs dans le monde et les publics qui s'intéressent à la Palestine. Le projet très contemporain du Palestinian Museum (qui est davantage un espace d'exposition, de témoignages, de débat qu'un lieu de conservation de collections) résume cette vocation des musées à être des acteurs de la construction identitaire et du maintien des liens entre les diverses composantes du peuple palestinien. «Je pense que le Palestinian Museum doit s'engager dans une identité en transformation car nous sommes encore sur le seuil d'établir un Etat. Je crois que l'histoire entière est toute la partie de la production de cette identité, qu'elle doit être réinterprétée dans un paysage changeant, je veux dire des frontières précaires qui définissent l'Etat nation qui sera un pays. Je pense à la diaspora qui vit dans divers lieux 
du monde et qui a différentes composantes d'identité avec un mélange de culture et de patrimoine auxquelles ces personnes de la diaspora sont confrontées ${ }^{17}$ ».

Si la ville de Ramallah émerge, pour ses acteurs culturels et politiques, comme un espace central et dynamique de culture au cœur des Territoires palestiniens occupés, elle demeure néanmoins une ville de repli, à défaut de voir Jérusalem-Est devenir la « capitale culturelle» de la Palestine (Gonzalez-Quijano, 2010). Quelle place donner donc à Ramallah, devenue la ville culturelle des Territoires occupés depuis le milieu des années 2000 grâce à ses théâtres, à ses musées, à son conservatoire de musique, à ses fondations privées, à ses manifestations, à ses institutions culturelles ?

\section{Ramallah dans l'ombre Jérusalem-Est : enjeux culturels et politiques}

Bien que se concentre à Ramallah une majorité des lieux de production, de médiation et de diffusion artistique (figure 1) faisant de la ville le poumon culturel et politique des TPO, Jérusalem-Est - située à une dizaine de kilomètres de Ramallah - demeure, pour de nombreux Palestiniens, la capitale culturelle et politique espérée de la Palestine.

Jérusalem-Est, sous occupation et contrôle israélien depuis 1967 et isolée du reste de la Cisjordanie depuis la construction du mur en 2000, est revendiquée par les autorités palestiniennes comme la capitale de la Palestine. Pourtant, bien que le Ministère de la Culture palestinien ait établi «l'unité de Jérusalem» afin d'y maintenir une présence culturelle (Farhat, 2011), depuis les accords d'Oslo en 1993, aucun Palestinien de Cisjordanie ou de la Bande de Gaza ne peut s'y rendre sans une myriade d'autorisations, et aucune manifestation ne peut s'y dérouler sous l'égide de l'Autorité palestinienne, car elles sont déclarées illégales par le gouvernement israélien. Par ailleurs, si Jérusalem-Est compte un nombre conséquent de structures culturelles, fruit d'ONG ou de fondations, construire à Jérusalem-Est un équipement institutionnel administré par l'Autorité palestinienne relève de l'impossible. En témoignent les propos du directeur du Palestinian Museum, en construction à Birzeit, dans la périphérie de Ramallah: «Ce musée était à l'origine supposé être construit à Jérusalem. La Welfare association a essayé de le faire car les musées nationaux sont dans la capitale nationale sauf qu'avec la situation politique, c'est impossible ${ }^{18}$ ». Bien que classé en 2009 par le Ministère palestinien du Tourisme et des Antiquités (Ministry of Tourism and Antiquities, 2009) au répertoire des musées, comme le Palestinian Archaeological Museum, le musée Rockfeller, situé à Jérusalem-Est, demeure sous contrôle israélien depuis 1967. Pour les Palestiniens, il constitue le musée national palestinien en état d'occupation et fait l'objet d'un profond sentiment identitaire. Cette représentation a pu perturber les projets de construction du musée de Yasser Arafat et du Palestian Museum à Ramallah, se heurtant à l'image politique emblématique du musée Rockfeller de Jérusalem-Est. Cette institution cristallise bien à la fois le conflit israélo-palestinien et le paradoxe de la visibilité entre Ramallah et Jérusalem-Est.

Pour les Palestiniens se pose en effet la question de la notoriété culturelle de Ramallah (Gonzalez-Quijano, 2010) face à Jérusalem-Est. Les difficultés rencontrées au moment de l'événement «Jérusalem, capitale culturelle arabe », manifestation créée en 1995 par les membres du groupe arabe à l'UNESCO, témoignent de l'ambiguïté d'une «capitale culturelle » en zone occupée et de la centralité prise par défaut par Ramallah. Entre les nombreuses interdictions, les visas refusés pour les artistes arabes invités, l'impossibilité pour les Palestiniens de Cisjordanie de franchir le mur, l'inauguration institutionnelle de 
l'édition "Jérusalem, capitale culturelle arabe » à Bethléem, les célébrations à Ramallah de plusieurs événements, certains membres des autorités publiques considèrent Jérusalem-Est comme leur capitale : «Jérusalem est notre capitale historique mais Israël nous empêche d'y aller. Alors pour cette raison, nous tenons ce festival dans d'autres villes jusqu'au jour où nous pourrons le faire à Jérusalem. Là, c'est pour montrer au monde que nous avons une capitale mais que nous ne pouvons pas nous y rendre ${ }^{19}$ ». Derrière l'événement culturel se jouent des revendications territoriales : si Ramallah est incontestablement un pôle culturel et politique crucial des TPO, elle n'est toutefois pas encore "capitale culturelle et politique». Pourtant la position de Ramallah pose question : «Ramallah, capitale sans Etat » (Barthe, 2010), ou encore «Ramallah : capitale culturelle de la Palestine? » (Workshop, Wein a Ramallah, 2011).

Pourtant la Municipalité de Ramallah mène une politique très volontaire et dynamique, en faveur de l'attractivité de la ville, en inscrivant les problématiques culturelles dans son projet de développement urbain : "nous ne sommes pas seulement une municipalité de balayage et de gardiennage mais notre rôle doit être plus développé et plus cohérent avec les besoins de la ville de Ramallah, qui est la capitale provisoire ou un centre culturel important au niveau de la patrie $\mathrm{e}^{20}$ ». L'engagement politique en faveur du rayonnement de Ramallah est assez notable, dans le territoire mais également à l'extérieur de la Cisjordanie et de la Palestine. Les derniers projets de construction d'équipements culturels poursuivent et renforcent cet engagement de portée internationale (musée Yasser Arafat, Centre Culturel de l'AM Qattan foundation, Ramallah National Exhibitions Center).

\section{BIBLIOGRAPHIE}

BARTHE B. (2010), « Ramallah, capitale sans Etat », L'Express.

BARTHE B. (2011), Ramallah Dream. Voyage au cœur du mirage palestinien, Paris, La Découverte, 256 p.

BSHARA K. (2005), “Opera Qais wa Yeman”, This Week in Palestine, 90.

DEBRAS B. (2011), « Territoire libéré », La Tribune \& Moi.

EL-HAGGAR N. (2004), Tenir bon en Palestine. Théâtre et développement, de l'émancipation à la résistance, Collection Essais, Editions Colophon, Lille.

FARHAT F. (2011), “Palestine”, pp. 150-173, in Cultural Policies in Algeria, Egypt, Jordan, Lebanon, Morocco, Palestine, Syria and Tunisia - An introduction, Amsterdam, Boekmanstudies, $271 \mathrm{p}$. GONZALEZ-QUIJANO Y. (2010), " Jérusalem, capitale "éternelle et indivisible" de la culture arabe?", Méditerranée, 114, pp. 131-133.

HABANE A., BOSREDON P., GRÉGORIS M.-T. (2012), « Les défis de la réhabilitation intégrée des villes palestiniennes : l'exemple de la vieille ville de Ramallah », Actes du colloque La ville, patrimoine vivant, Salé (Maroc), 11-12 octobre 2012, pp. 103-109 
HEACOCK R. (2013), « Ramallah: la vie sur un volcan éteint », Confluences Méditerranée, 86, pp. 43-56.

LEBHOUR K. (2009), Jérusalem, capitale culturelle arabe hors les murs, RFI.

MINISTRY OF CULTURE (2010), Palestinian National Plan 2011-13 - Culture Sector Strategic Plan Summary, $20 \mathrm{p}$.

MINISTRY OF TOURISM AND ANTIQUITIES, 2009, Directory of Museums in Palestine, 43 p.

PORTEILLA R., FONTAINE J., ICARD P., LARCENEUX A. (2011), Quel Etat ? Pour quelle Palestine?, Paris, L'Harmattan, $431 \mathrm{p}$.

SLITINE M. (2013), " The "worlds of the art" in Palestine », séminaire Heritage, culture and urban renewal, Université Lille 1.

\section{NOTES}

1. Cet article se fonde sur un travail de terrain réalisé dans le cadre du projet émergent : « Culture et recomposition des espaces urbains (Territoires palestiniens occupés, France, Maroc) » financé par la MESHS Lille-Nord de France (2014) et du projet «Renouvellement Urbain et Milieux Culturels et Artistiques dans les Territoires palestiniens occupés » soutenu par le programme « Sociétés en Méditerranée - SOCMED » du CNRS-INSHS et de l'IRD (2013). Equipe des chercheurs du laboratoire TVES EA 4477 : Bosredon Pauline (responsable scientifique), Gravereau Sophie, Grégoris Marie-Thérèse et Habane Anissa.

2. Recensement de 2007 du Palestinian Central Bureau of Statistics (PCBS).

3. Compte-rendu d'activité de l'association Al-Kamandjâti en août 2003 . http:// www.alkamandjati.com/media/compte_rendu_ete__2003__003427400_1913_24022010.pdf

4. Le terme « arme » a été utilisé à plusieurs reprises par des acteurs interrogés, comme par exemple, le responsable de l'association Human Supporters à Naplouse interviewé par A. Habane en décembre 2012: «Nous avons un groupe de dabké pour montrer que les Palestiniens ont une culture. Nous utilisons la danse et la musique comme une arme pour lutter contre l'occupation. Nous avons réussi à sortir du blocus et à aller à l'extérieur pour montrer notre culture et refléter notre souffrance. Nous sommes partis en France en 2010 à Nanterre, à Nantes, à Paris et en Italie à Rome en 2012. Nous voulons résister par les pratiques culturelles avec la danse et la musique ». De même, le Ministère de la Culture palestinien utilise cette métaphore dans le Strategic Plan for the Cultural Sector mis en œuvre pour la période 2011-2013 : As it is capable of providing perseverance capacities and enriching the national identity, culture is a significant weapon in the liberation battle (Ministry of Culture, 2010, p. 2).

5. Le hosh est un complexe résidentiel traditionnel composé de plusieurs unités d'habitation autour d'une cour centrale.

6. Entretien réalisé par M-T. Grégoris et A. Habane avec le Service culturel de la Municipalité de Ramallah en août 2012.

7. Entretien conduit par A. Habane avec le Directeur de l'association "Dar Qandeel for arts and culture" en août 2012 et avec plusieurs membres de l'association à Tulkarem en novembre 2012.

8. Entretien fait par P. Bosredon avec Sally Abubakar du Département des affaires sociales et culturelles de la Municipalité de Ramallah en mars 2014.

9. Entretien réalisé par A. Habane avec le Service urbanisme de la Municipalité de Ramallah en avril 2014. 
10. Entretien mené par P. Bosredon avec Sally Abubakar du Département des affaires sociales et culturelles de la Municipalité de Ramallah en mars 2014.

11. Ibid.

12. Entretien effectué par P. Bosredon, S. Gravereau et M-T Grégoris avec le propriétaire de Dar Zahran à Ramallah en mars 2014.

13. Entretien fait par P. Bosredon, S. Gravereau et M-T Grégoris avec la responsable de la Gallery One à Ramallah en mars 2014.

14. http://www.pcbs.gov.ps/default.aspx

15. Il s'agit d'une publication, éditée pour la première fois en décembre 1998 par Turbo Design, maison d'édition installée à Ramallah dont le directeur général et propriétaire est l'homme d'affaires palestinien Sani Meo, personnalité incontournable du monde culturel en Palestine.

16. Entretien conduit par A. Habane à Naplouse en novembre 2012.

17. Entretien réalisé par P. Bosredon, M-T. Grégoris et A. Habane avec Jack Persekian, Directeur du Palestinian Museum, à Ramallah en mars 2014.

18. Ibid.

19. Propos de la Directrice du ministère de la Jeunesse et des Sports à Ramallah rapportés par Karim Lebhour (2009).

20. Propos recueillis par A. Habane au cours de l'intervention de Fatin Farhat, la Responsable du service de la Culture à la Municipalité de Ramallah, lors du Workshop organisé pendant le Festival Wein à Ramallah en juillet 2011.

\section{RÉSUMÉS}

Étudier les relations entre culture et espace dans les Territoires Palestiniens Occupés (TPO) nous invite à nous interroger sur les liens entre art, patrimoine, revendications politiques et développement territorial: l'histoire récente de la Cisjordanie a démontré le rôle de l'engagement artistique et culturel des édiles locaux, nationaux et des organismes internationaux dans la reconquête des centres-villes anciens et dans l'affirmation d'une identité palestinienne. L'objectif de cet article est de comprendre les mécanismes à travers lesquels les acteurs culturels, au sens large, cherchent à créer une nouvelle centralité culturelle au cœur des TPO.

Studying the relationship between culture and space in the occupied Palestinian territories (OPT) invites us to interrogate the relationship between art, heritage, political claims and territorial development: the recent history of the West Bank has demonstrated the role of the artistic engagement and cultural development of the political stakeholders in the reconquest of the old city centers and in the affirmation of Palestinian identity. The aim of this scientific paper is to understand the mechanisms through which cultural actors, in the broad sense, seek to create a new cultural centrality in the heart of the oPt.

\section{INDEX}

Mots-clés : culture, développement urbain, patrimoine, Palestine, Ramallah, résistance

Keywords : heritage, urban development 


\section{AUTEURS}

\section{PAULINE BOSREDON}

Université Lille1, Laboratoire TVES, Pauline.Bosredon@univ-lille1.fr

\section{SOPHIE GRAVEREAU}

Université du Littoral-Côte-d'Opale, Laboratoire TVES, sophie.gravereau@free.fr

\section{MARIE-THÉRÈSE GRÉGORIS}

Université Lille1, Laboratoire TVES, marie-therese.gregoris@univ-lille1.fr

ANISSA HABANE

Université Lille1, Laboratoire TVES, Anissa.Habane@univ-lille1.fr 